\title{
The New Open Economy Macroeconomics of Government Debt
}

\author{
Giovanni Ganelli*
}

This Version: October 2002

\begin{abstract}
In this paper we introduce an overlapping generations structure of the Blanchard type in a New Open Economy Macroeconomics model. This allows us to study a wider range of fiscal shocks compared to the traditional Mundell-Fleming and to the baseline Redux models. One important policy implication of our model is that the tax cut implemented in the US in 2001 might have contributed to the appreciation of the Dollar vis-a-vis the Euro. In contrast, the imposition of fiscal constraint such as the "Golden Rule" proposed by the UK government can have opposite exchange rate effects.

Keywords: overlapping generations, new open economy macroeconomics, debt, tax cut.

JEL Codes: F41, F31, H63
\end{abstract}

I would like to thank Neil Rankin for inspiring this paper and for his help and support. I am also grateful for useful comments to Paola

\footnotetext{
* Correspondence: Department of Economics and Institute for International Integration
} Studies, Trinity College Dublin, Dublin 2, IRELAND. Email: ganellig@tcd.ie Tel.: 353-16083044. Fax: 353-1-6772503. 
Caselli, Giancarlo Corsetti, Philip Lane, Lucio Sarno, Simon WrenLewis and seminar participants at Trinity College Dublin, Ente Einaudi (Rome) and at the Money Macro and Finance 2002 Conference. This work is part of a research network on 'The Analysis of International Capital Markets: Understanding Europe's Role in the Global Economy', funded by the European Commission under the Research Training Network Programme (Contract No. HPRN-CT-1999-00067). 


\section{Introduction}

The study of the international effects of fiscal policy shocks is a classical exercise in open-economy macroeconomics, that dates back at least to the original development of the Mundell-Fleming (MF) model. ${ }^{1}$ Fiscal policy, however, has received comparatively less attention than monetary policy in recent theoretical research based on microfounded, general-equilibrium models with imperfect competition and nominal rigidities.

An obvious example of this unbalance can be found in the development of the New Open Economy Macroeconomics (NOEM) literature. ${ }^{2}$ In surveying this field of research Lane (2001, p. 236), makes a point of focusing almost completely on the analysis of monetary shocks because "This reflects the emphasis in the literature". The fact that the potential of the NOEM framework to study fiscal shocks has been only marginally exploited so far is surprising, especially considering that an explicitly intertemporal setting provides the potential for spelling out in much more detail, compared to the traditional Mundell-Fleming (MF) approach, the effects of the different components of a fiscal expansion.

While there is little doubt about the fact that a monetary shock implies a surprise change in the interest rate, a fiscal shock can be implemented in many different ways. Since the government can use taxes, spending and debt as fiscal instruments, any change in the mix of two of these variables, keeping the third one constant, represents a different prototype of fiscal shock. In spite of this, the few existing papers in the NOEM literature that analyse

\footnotetext{
${ }^{1}$ Mundell (1968), Fleming (1962).

${ }^{2}$ The NOEM approach combines perfect foresight and optimising behaviour with market imperfections such as imperfect competition and nominal rigidities. The starting point of this literature is usually considered to be the Redux model provided by Obstfeld and Rogoff (1995). Lane (2001) and Sarno (2000) provide excellent surveys. Ganelli and Lane (2002) focus on more recent developments in the field.
} 
fiscal issues limit their analysis to balanced-budget policies. ${ }^{3}$

In this paper we develop a non-Ricardian general equilibrium model with imperfect competition and sticky prices that can be used to shed some light on issues like the effects of different types of fiscal shocks on the exchange rate and on other macroeconomic variables, and the consequences of imposing constraints that limit the fiscal stance of governments.

One policy implication of the model is that if a government decides to boost the economy through an expansionary fiscal policy, in the short run its currency will appreciate if the chosen instrument is a tax-cut, but it will depreciate if it is a balanced-budget spending increase. This suggests that the tax-cut package approved by the Bush Administration in 2001 might be one of the determinants of the recent appreciation of the Dollar. ${ }^{4}$

The intuition behind this result is that, because in a model in which Ricardian equivalence does not hold government bonds are perceived as net wealth by economic agents, a reduction in taxes financed by government debt increases short-run consumption. Since domestic consumption increases more than foreign consumption, the pressure on relative money demand appreciates the domestic currency.

On the contrary, if the expansion is carried out through a balanced-budget policy, the negative wealth effect associated with the fact that domestic residents have to pay higher taxes can depress relative consumption, therefore reducing the demand for money and creating a pressure for depreciation of the currency. According to the predictions of this model, therefore, the imposition of fiscal constraint such as the "Golden Rule" proposed by the

\footnotetext{
${ }^{3}$ Obstfeld and Rogoff (1995, 1996), Caselli (2001), Corsetti and Pesenti (2001) and Ganelli (2000) analyse balanced-budget policies in a NOEM framework.

${ }^{4}$ As we stress below (see Section 4), it is not our intention to claim that the appreciation of the Dollar in recent years can be attributed only to the tax cut. We rather argue that the fiscal stimulus is one of the many factors that contributed to the strenght of the US currency.
} 
UK government imply that, for a given amount of government spending, the exchange-rate effect of a fiscal shock will be a reduction of the external value of the currency. The model therefore predicts that the fiscal measures announced by Chancellor Gordon Brown in the March 2002 Budget, including a 43 percent rise in health spending to be financed mainly by an increase in $\mathrm{Na}$ tional Insurance contributions, will not contribute to a further appreciation of the Pound.

From a technical point of view, the model presented in this paper breaks down Ricardian equivalence in the NOEM framework by combining the $R e$ dux (Obstfeld and Rogoff 1995, 1996) model with an overlapping generations structure of the Blanchard (1985) type. This allows us to make a step forward in studying the international effects of government debt in the NOEM framework. ${ }^{5}$

A model that analyses the interaction between monetary and fiscal policy in a framework characterized by imperfect competition, nominal rigidities and non-Ricardian agents is provided by Leith and Wren-Lewis (2002). In spite of some similarities in the modelling strategy, our contribution can be considered orthogonal to theirs. One important difference is that they model a monetary union, while we focus on the flexible-exchange rate case. The endogenous reaction of the exchange rate to debt policies allows us to study fiscal spillovers between (rather than within) monetary areas.

In addition to contributing to the analysis of important policy issues such as the above mentioned ones, our model can also reconcile the old and the

\footnotetext{
${ }^{5}$ Obstfeld and Rogoff stress the importance of studying this issue as follows: "Introducing overlapping generations in place of homogeneous infinitely lived agents would enrich the dynamics while permitting real effects of government budget deficits" (Obstfeld and Rogoff, 1995, pag.654). Ghironi (2000) combines the NOEM framework with infinitely-lived generations of the Weil (1989) type. He shows how introducing overlapping generations can solve the "stationarity problem" displayed by several models in the literature.
} 
new paradigms for the analysis of fiscal policy interdependence with respect to the short-run spillover effects on output. In the original Redux framework, the effect of a fiscal shock on for eign output is negative, i.e. opposite to the one derived in the two-country version of the MF model. ${ }^{6}$ In our model, the expenditure-switching effect due to the short-run appreciation of the exchange rate implies that the short-run output spillover of a debt-financed tax reduction is unambiguously positive. Introducing a finite time horizon therefore reconciles the NOEM framework with the MF tradition on this point.

The structure of the paper is the following: the next section introduces the model; section 3 derives and discusses the macroeconomic effects of government debt; section 4 discusses more in depth the policy implications of the theoretical analysis already pointed out in this introduction; section 5 concludes.

\section{The Model}

There are two countries in the world that we label Home and Foreign. In each period $n$ individuals are born in the Home country and $1-n$ in the Foreign country. In each period every agent faces a constant probability of death, that is the same across countries, equal to $(1-q)$. Home population is therefore $\sum_{a=0}^{\infty} q^{a} n=\frac{n}{1-q}$. Accordingly, Foreign population is $\frac{1-n}{1-q}$ and world population is $\frac{1}{1-q}$. There is also a measure 1 of (infinitely lived) firms in the world, $n$ of these are located in the domestic country, $1-n$ in the foreign country. Firms have monopolistic power in the production of a differentiated good. Both the firms and the goods that they produce are indexed by $z \epsilon[0,1]$.

The consumption of good $z$ by domestic and foreign agents of age $a$ is given by

\footnotetext{
${ }^{6}$ For a formal derivation, see Ganelli (2000).
} 


$$
\begin{aligned}
& C_{a, t}=\left[\int_{0}^{1} c_{a}(z)^{\frac{\theta-1}{\theta}} d z\right]^{\frac{\theta}{\theta-1}} \\
& C_{a, t}^{*}=\left[\int_{0}^{1} c_{a}^{*}(z)^{\frac{\theta-1}{\theta}} d z\right]^{\frac{\theta}{\theta-1}}
\end{aligned}
$$

where $\theta>1$ is the elasticity of substitution between any pair of goods. The corresponding price indexes are

$$
\begin{aligned}
P & =\left[\int_{0}^{1} p(z)^{(1-\theta)} d z\right]^{\frac{1}{1-\theta}} \\
P^{*} & =\left[\int_{0}^{1} p^{*}(z)^{(1-\theta)} d z\right]^{\frac{1}{1-\theta}}
\end{aligned}
$$

where $p(z)$ and $p^{*}(z)$ are respectively the domestic and foreign currency price of good $z$. We assume that the law of one price holds. This means that, denoting with $E$ the nominal exchange rate (the price of foreign currency in terms of home currency), the following relationship holds for each good

$$
p(z)=E p^{*}(z)
$$

where $p(z)$ and $p^{*}(z)$ are the prices of the same good respectively in home and foreign currency. It follows that the home and foreign consumer prices indexes are linked by the Purchasing Power Parity (PPP)

$$
P=E P^{*}
$$

\subsection{Production}

The total (private plus public), demand for good $z$ can be derived as follows 


$$
\begin{aligned}
Y_{t}(z) & =\left[\frac{p(z)}{P}\right]^{-\theta} \sum_{a=0}^{\infty}\left\{n q^{a} C_{a, t}+n q^{a} G_{t}\right\}+\left[\frac{p^{*}(z)}{P^{*}}\right]^{-\theta} \sum_{a=0}^{\infty}\left\{(1-n) q^{a} C_{a, t}^{*}+(1-n) q^{a} G_{t}^{*}\right\}= \\
& =\left[\frac{p(z)}{P}\right]^{-\theta}\left(C^{w}+G^{w}\right)
\end{aligned}
$$

where $C^{w}+G^{w}$ is world total (private plus public) consumption of the composite good. ${ }^{7} G_{t}$ is to be interpreted as home government spending percapita, and an analogous interpretation holds for $G_{t}^{*}{ }^{8}$ We assume that the composition of public consumption is the same as the one of private consumption. In deriving the latter expression, we have also made use of the law of one price and of the PPP, which implies $\frac{p(z)}{P}=\frac{p^{*}(z)}{P^{*}} . Y_{t}(z)$ is the demand for output per-firm. Since the $n$ domestic firms behave symmetrically, aggregate output for the Home country is given by $n Y_{t}(z)$. Dividing the latter by the size of the domestic population we get per-capita Home output as $Y^{P C}=$ $Y_{t}(z)(1-q)$. Equation (5) then implies

$$
Y_{t}^{P C}=\left[\frac{p(z)}{P}\right]^{-\theta}\left(C^{w, P C}+G^{w, P C}\right)
$$

We assume that domestic firms only hire domestic agents and foreign firms only hire foreign agents in a perfectly competitive labour market. Furthermore, the only production factor is labour, with constant returns, and productivity is independent of age. The production of each firm is therefore equal to labour input according to the production function: $Y_{t}(z)=L_{t}$. With imperfect competition in the goods market, the profit maximising conditions for domestic and foreign firms are given by the expressions

$$
W_{t}=\frac{\theta-1}{\theta} P_{t}(z)
$$

${ }^{7}$ Throughout the paper the superscript $w$ denotes world variables, while $P C$ denotes per-capita variables.

${ }^{8}$ We assume that this variable is distributed independently of age. Individual and per-capita therefore coincide for it. 
and

$$
W_{t}^{*}=\frac{\theta-1}{\theta} P_{t}^{*}(z)
$$

where $W_{t}$ and $W^{*}{ }_{t}$ are domestic and foreign nominal wages.

\subsection{Private Agents}

We now describe the optimisation problem of a representative domestic agent of age $a .^{9}$ Private agents derive utility from consumption, leisure and real balances. In order to make aggregation across ages possible, we assume that preferences are homothetic and separable in each component of the utility function. The endowment of time in each period is normalized to 1 . In the exposition of individual variables that follows, the first index refers to the age of the agents and the second to time. Therefore, $L_{a, t}$ is the quantity of labour supplied in every period by the agents of age a at time $t$, and $\left(1-L_{a, t}\right)$ is the agent's leisure. ${ }^{10}$

A standard assumption in this framework is the existence of insurance companies. We assume that insurance companies pay a net premium of $\left(\frac{1-g}{q}\right)$ on the agent's financial wealth for each period in which the agent is alive, while they encash the agent's financial wealth if the agent dies.

Agents can hold financial wealth as real balances or as assets. Assets held by domestic agents can take the form either of a credit against private foreign agents or of government debt. In order to simplify the notation, we assume that all assets are defined in terms of the composite consumption good. Agents hold the amount of assets that maximizes their expected utility but they are indifferent to the composition of assets. In addition, Home agents supply labour in the perfectly competitive labour market, receive shares of

\footnotetext{
${ }^{9}$ The optimization problem of the foreign agent, being analogous to the domestic one, will not be presented in detail.

${ }^{10}$ An analogous notation holds for the other variables.
} 
profits from domestic firms and pay lumps-sum taxes. A domestic representative agent of age $a$ therefore maximizes

$$
\begin{aligned}
E\left(U_{t}\right)= & \sum_{s=t}^{\infty}(\beta q)^{s-t}\left[\log \left(C_{a+s-t, s}\right)+\chi \log \frac{M_{a+s-t, s}}{P_{s}}+\right. \\
& \left.+\psi \log \left(1-L_{a+s-t, s}\right)\right]
\end{aligned}
$$

subject to the budget constraint

$$
\begin{aligned}
F_{a, t+1}+\frac{M_{a, t}}{P_{t}}+C_{a, t}= & \frac{1}{q}\left[\frac{M_{a-1, t-1}}{P_{t}}+\left(1+r_{t}\right) F_{a-1, t}\right]+ \\
& +\frac{W_{a, t}}{P_{t}} L_{a, t}+\frac{\Pi_{t}}{P_{t}}-\tau_{t}
\end{aligned}
$$

where $0<\beta<1$ is the discount factor, $\chi$ and $\psi$ positive parameters and $\frac{\Pi_{t}}{P_{t}}=\pi_{t}(h)(1-q)$ is the per-capita quota of domestic profits. ${ }^{11} F$ denotes total assets holdings of the agent, $r_{t}$ is the real interest rate on bonds between $t-1$ and $t, M_{t-1}$ nominal money balances held at the beginning period $t$ and $\tau_{t}$ lump-sum taxes payable in the consumption good. ${ }^{12}$ The first order conditions with respect to consumption, leisure and money holdings yield the following expressions

$$
\begin{gathered}
C_{a, t}=\left(\frac{1-q \beta}{1+\chi+\psi}\right)\left\{\left(1+r_{t}\right) \frac{1}{q}\left[\frac{1}{1+i_{t}} \frac{M_{a-1, t-1}}{P_{t-1}}+F_{a-1, t}\right]+H_{a, t}\right\} \\
L_{a, t}=1-\psi \frac{P_{t}}{W_{a, t}} C_{a, t}
\end{gathered}
$$

\footnotetext{
${ }^{11}$ We assume that taxes and profits of domestic firms are equally distributed across domestic agents (and viceversa), independently of age. A uniform distribution across agents, while obviously a simplification made for the sake of tractability, is not uncommon in the literature (see, for example, Hau 2000). Note that, with $n$ symmetric firms in the country, aggregate profits are given by $n \pi_{t}(h)$, where the index $h$ denotes a representative domestic firm. Dividing the latter by the size of the country's population $\frac{n}{(1-q)}$, we get $\pi_{t}(h)(1-q)$.

${ }^{12}$ We adopt Obstfeld and Rogoff (1996) timing convention, $M_{t}$ therefore denotes money between period $t$ and period $t+1$, while $F_{t}$ denotes bonds between period $t-1$ and $t$.
} 


$$
\frac{M_{a, t}}{P_{t}}=\chi \frac{\left(1+i_{t+1}\right)}{i_{t+1}} C_{a, t}
$$

Where $i_{t}$ is the real interest rate on bonds between $t-1$ and $t$. Equation (9) gives individual consumption demand as a function of financial and human wealth. The expression $\frac{1-q \beta}{1+\chi+\psi}$ in (9) is the constant propensity to consume out of total (financial plus human) wealth. The propensity to consume is an inverse function of the weights on real balances and leisure in the utility function $(\chi$ and $\psi)$ and of the agent's temporal horizon (it decreases as the effective discount factor $q \beta$ increases). Human wealth is given by

$$
H_{a, t}=\sum_{s=t}^{\infty} \alpha_{s, t} q^{s-t}\left(\frac{w_{a+s-t, s}}{P_{s}}+\frac{\Pi_{t}}{P_{s}}-\tau_{s}\right)
$$

Where $\alpha_{s, t}$ is the present value factor, defined as

$$
\alpha_{s, t}=1 \text { when } s=t \text {, and }
$$

$\alpha_{s, t}=\frac{1}{\left(1+r_{t+1}\right) \ldots . .\left(1+r_{s}\right)}$ when $s>t$. Human wealth is defined as the present discounted value of potential gross earnings (that would be earned if the agent chose to consume no leisure) plus profits minus taxes. However, since leisure provides utility, agents will not choose to supply a quantity 1 of work in each period. This is shown by equation (10). ${ }^{13}$ To gain some intuition on the meaning of equation (10), it is useful to rearrange it as

$$
\left(1-L_{a, t}\right) W_{a, t}=\psi P_{t} C_{a, t}
$$

The above expression tells us that there is an inverse proportionality between expenditure on consumption and expenditure on leisure (defined in terms of the opportunity cost of not working). Finally, equation (11) expresses the fact that demand for real balances is a positive function of consumption and a negative function of the nominal interest rate.

\footnotetext{
${ }^{13}$ Note that, when leisure does not provide utility $(\psi=0)$, equation $(10)$ implies that the agent inelastically supplies the unitary endowment of time for production.
} 
Summing across ages the above individual first order conditions and dividing them by the size of the domestic population, we derive the following per-capita demand functions

$$
\begin{gathered}
C_{t}^{P C}=\left(\frac{1-q \beta}{1+\chi+\psi}\right) T W_{t}^{P C} \\
\frac{M_{t}^{P C}}{P_{t}}=\chi \frac{\left(1+i_{t+1}\right)}{i_{t+1}} C_{t}^{P C} \\
L_{t}^{P C}=1-\psi \frac{P_{t}}{p_{t}(z)} \frac{\theta}{\theta-1} C_{t}^{P C}
\end{gathered}
$$

where $T W_{t}^{P C}$ is total (financial plus human) per-capita wealth, given by

$$
T W_{t}^{P C}=\sum_{a=0}^{\infty}(1-q) q^{a} T W_{t}=H_{t}^{P C}+\left(1+r_{t}\right)\left[\frac{1}{1+i_{t}} \frac{M_{t-1}^{P C}}{P_{t-1}}+F_{t}^{P C}\right](16)
$$

and

$$
\begin{gathered}
H_{t}^{P C}=\sum_{a=0}^{\infty}(1-q) q^{a}\left\{\sum_{s=t}^{\infty} \alpha_{s, t} q^{s-t}\left(\frac{W_{s}}{P_{s}}+\frac{\Pi_{t}}{P_{s}}-\tau_{s}\right)\right\}=\sum_{s=t}^{\infty} \alpha_{s, t} q^{s-t}\left(\frac{W_{s}}{P_{s}}+\frac{\Pi_{s}}{P_{s}}-\tau_{s}\right) \\
M_{t-1}^{P C}=\sum_{a=0}^{\infty}(1-q) q^{a-1} M_{a-1, t-1} \\
D_{t}^{P C}=\sum_{a=0}^{\infty}(1-q) q^{a-1} D_{a-1, t}
\end{gathered}
$$

Notice that, in the aggregation of wealth, we have used the fact that both taxes and real wages are invariant across ages. As a consequence, per-capita human wealth is equal to individual wealth for each agent. In equation (15) we have replaced the nominal wage with the expression deriving from the profit maximization problem of the firms. 
It is also possible to derive the following law of motion for per-capita consumption

$$
C_{t+1}^{P C}=\left(\frac{1-q \beta}{1+\chi+\psi}\right)(1-q) H_{t+1}+\left(1+r_{t+1}\right) q \beta C_{t}^{P C}
$$

In the case of infinite life $(q=1)$ equation (18) reduces to a standard Euler equation. In that case human wealth is not important for predicting future consumption. ${ }^{14}$

\subsection{The Government}

Government expenditure and interest payments on outstanding debt can be financed by seigniorage, lump-sum taxes and issuing of new debt, according to the single-period budget constraint ${ }^{15}$

$$
G_{t}+\left(1+r_{t}\right) D_{t}=\tau_{t}+\frac{\left(M_{t-} M_{t-1}\right)}{P_{t}}+D_{t+1}
$$

An analogous budget constraint holds for the foreign government.

\subsection{Net Foreign Assets}

Integrating the agents' private budget constraint across ages, and substituting for $\tau_{t}$ from the government budget constraint, we derive the following

\footnotetext{
${ }^{14}$ Frenkel and Razin (1996) develop a discrete time version of Blanchard (1985) model, in which money and leisure do not provide utility and the intertemporal elasticity of substitution of consumption can differ from unity. Equation (18) nests the Frenkel and Razin logarithmic case when $\chi=\psi=0$.

${ }^{15}$ In addition, the government must also respect a No-Ponzi game condition. Since the government has an infinite life horizon, the real interest rate applied to $D_{t}$ in the government budget constraint is $\left(1+r_{t}\right)$, as opposed to $\frac{\left(1+r_{+}\right)}{q}$ in the private agents' budget constraint.
} 
expression in aggregate terms ${ }^{16}$

$$
\begin{aligned}
F_{t+1}-F_{t}= & \frac{\theta-1}{\theta} \frac{p_{t}(h)}{P_{t}} L_{t}+r_{t} F_{t}-C_{t}-G_{t}+ \\
& +D_{t+1}-\left(1+r_{t}\right) D_{t}+\frac{\Pi_{t}}{P_{t}}
\end{aligned}
$$

where, with obvious notation, $p_{t}(h)$ is the price set by a typical home firm in a symmetric equilibrium across firms. Defining net foreign assets as $V=F-D$, and dividing both sides by the size of the domestic population, we obtain a current account equation in per-capita terms as follows

$$
\begin{aligned}
V_{t+1}^{P C}-V_{t}^{P C}= & \frac{\theta-1}{\theta} \frac{p_{t}(h)}{P_{t}} L_{t}^{P C}-C_{t}^{P C}-G_{t}^{P C}+ \\
& +\frac{\prod_{t}}{P_{t}}+r_{t} V_{t}^{P C}
\end{aligned}
$$

The definition of net foreign assets is similar to the one used by Obstfeld and Rogoff $(1995,1996)$ to denote the net position towards the other country. In our framework, however, the term "net" also indicates the fact that this variable is net of assets issued by the domestic government. In the aggregate the following must hold at any time: $V=-V^{*}$. This implies the following relationship in per-capita terms $n V^{P C}=-(1-n) V^{P C *}$.

We assume that parameters do not vary across countries. Therefore, a set of equations that are the equivalent of (6), (13), (14), (15), (18) and (20) hold for the foreign country, together with an analogous budget constraint for the foreign government.

\footnotetext{
${ }^{16}$ Notice that in this equation we have replaced the nominal wage with its value implied by the profit maximization condition.
} 


\subsection{The Initial Steady State}

Since the model does not yield closed-form solutions, in order to assess the macroeconomic impact of fiscal policy we need to define a convenient initial steady state around which we log-linearize the equations.

Similarly to Obstfeld and Rogoff $(1995,1996)$ and Ganelli (2000), we consider an initial steady state in which net foreign assets, government spending and government debt are all zero. We accordingly denote this steady state using the subscript $0: V_{0}=0, V_{0}^{*}=0, D_{0}=0, D_{0}^{*}=0, G_{0}=0, G_{0}^{*}=0$. Perfect initial symmetry also implies that $\frac{p_{0}(z)}{P_{0}}=\frac{p_{0}^{*}(z)}{P_{0}^{*}}=1$. In a steady state defined in this way, the initial per-capita values of output and consumption take, in both countries, the following value

$$
C_{0}^{P C}=Y_{0}^{P C}=C_{0}^{* P C}=Y_{0}^{* P C}=C_{0}^{w, P C}=Y_{0}^{w, P C}=\frac{\frac{\theta-1}{\theta}}{\frac{\theta-1}{\theta}+\psi}
$$

When the elasticity of substitution $\theta$ tends to infinity, the system approaches perfect competition. In that case the steady-state value of consumption and output is equal to $\frac{1}{1+\psi}$, that is bigger than the expression given in (21), consistently with the intuition on the role of imperfect competition in bringing the economy to a sub-optimal steady state.

Equation (21) implies that the initial steady-state level of human wealth is, for both countries ${ }^{17}$

$$
H_{0}=H_{0}^{*}=\left\{\frac{\theta-1}{\theta}+\frac{1}{\theta} \frac{\frac{\theta-1}{\theta}}{\frac{\theta-1}{\theta}+\psi}\right\} \frac{R_{0}}{R_{0}-q}
$$

where $R$ is the gross real interest rate defined as $R=1+r$. In order to find an expression for the initial real interest rate, we can substitute the above expression, together with the steady-state value for consumption, in to the law of motion of consumption (18).

\footnotetext{
${ }^{17}$ Our choice of the initial steady state implies $\tau_{0}=0$.
} 
The terms in $\theta$ cancel out, and we find that the solution for the initial gross real interest rate is the same found in the perfect-competition model presented in Ganelli (2001), for the case of no initial debt. This is implicitly given by the equation

$$
R_{0}^{2}=\left\{q+\frac{1}{q \beta}\left[1-\left(\frac{1-q \beta}{1+\chi+\psi}\right)(1-q)(1+\psi)\right]\right\} R_{0}-\frac{1}{\beta}=0
$$

The solution for the real interest rate, therefore, is not affected by the assumption of imperfect competition. The intuition for this result is that the real interest rate is the intertemporal price of a consumption aggregate, that does not depend on the elasticity of substitution between the differentiated goods that are aggregated in it. Although equation (22) is a quadratic expression, it is possible to show that only one solution for $R_{0}$ corresponds to a well-defined steady state, in which we have $R_{0}>\frac{1}{\beta} .{ }^{18}$

In what follows we log-linearize the model around the initial steady state. As in Obstfeld and Rogoff $(1995,1996)$ and Ganelli (2000), the variables whose initial value is zero will be normalized using the value of initial consumption given in (21).

\subsection{Log-Linearization}

The set of (per-capita) log-linearized equations that we will use to solve the model is given below. Because of the simple way in which we will introduce nominal rigidities, variables adjust to their long-run values in the period after the shock. Hats therefore denote long-run (the period after the shock) logdeviations, and tildes short-run (the period of the shock) ones. Log-linear variables are in lower cases. The price set by a typical foreign firm in a

\footnotetext{
${ }^{18}$ See Ganelli (2001) for the details. Notice that, because of the presence of overlapping generations, the steady-state value of the real interest rate is not tied down by the discount factor how it would be in an infinite-horizon model.
} 
symmetric equilibrium is denoted by $\widetilde{p}(f)$.

$$
\begin{aligned}
& \widetilde{p}=n \widetilde{p}(h)+(1-n)\left[\widetilde{e}+\widetilde{p}^{*}(f)\right] \\
& \widetilde{p}^{*}=n[\widetilde{p}(h)-\widetilde{e}]+(1-n)\left[\tilde{p}^{*}(f)\right] \\
& \widetilde{y}=\theta\left[\widetilde{p}-\widetilde{p}(h]+\widetilde{c}^{w}+\widetilde{g}^{w}\right. \\
& \widetilde{y}^{*}=\theta\left[\widetilde{p}^{*}-\widetilde{p}^{*}(f)\right]+\widetilde{c}^{w}+\widetilde{g}^{w} \\
& \widehat{l}=\widehat{y}=-\psi \frac{\theta}{\theta-1}(\widehat{c}+\widehat{p}-\widehat{p}(h)) \\
& \widehat{l}^{*}=\widehat{y}^{*}=-\psi \frac{\theta}{\theta-1}\left(\widehat{c}^{*}+\widehat{p}^{*}-\widehat{p}^{*}(f)\right) \\
& \widehat{c}=\frac{(1-q \beta)}{(1+\chi+\psi)}(1-q)(1+\psi) \frac{R_{0}}{R_{0}-q} \widehat{h}+q \beta R_{0} \widetilde{c}+q \beta\left(R_{0}-1\right) \widetilde{r} \\
& \widehat{c}^{*}=\frac{(1-q \beta)}{(1+\chi+\psi)}(1-q)(1+\psi) \frac{R_{0}}{R_{0}-q} \widehat{h}^{*}+q \beta R_{0} \widetilde{c}^{*}+q \beta\left(R_{0}-1\right) \widetilde{r} \\
& \widehat{h}=(-\widehat{p}+\widehat{p}(h))+\frac{1}{\theta(1+\psi)} \widehat{y}-\frac{q}{R_{0}-q} \widehat{R}-\frac{1}{1+\psi} \widehat{\tau} \\
& \widehat{h}^{*}=\left(-\widehat{p}^{*}+\widehat{p}^{*}(f)\right)+\frac{1}{\theta(1+\psi)} \widehat{y}^{*}-\frac{q}{R_{0}-q} \widehat{R}-\frac{1}{1+\psi} \widehat{\tau}^{*} \\
& \widetilde{m}-\widetilde{p}=\widetilde{c}-\frac{\widetilde{r}}{R_{0}}-\left(\frac{\widehat{p}-\tilde{p}}{R_{0}-1}\right)
\end{aligned}
$$




$$
\begin{gathered}
\widetilde{m}^{*}-\widetilde{p}^{*}=\widetilde{c}^{*}-\frac{\widetilde{r}}{R_{0}}-\left(\frac{\widehat{p}^{*}-\widehat{p}^{*}}{R_{0}-1}\right) \\
\widehat{m}-\widehat{p}=-\frac{\widehat{r}}{R_{0}}+\widehat{c} \\
\widehat{m}^{*}-\widehat{p}^{*}=-\frac{\widehat{r}}{R_{0}}+\widehat{c}^{*} \\
\widehat{c}=\left(R_{0}-1\right) \widehat{v}-\widehat{p}+\widehat{p}(h)+\widehat{y}-\widehat{g} \\
\widehat{c}^{*}=\left(R_{0}-1\right) \widehat{v}^{*}-\widehat{p}^{*}+\widehat{p}^{*}(f)+\widehat{y}^{*}-\widehat{g}^{*} \\
\widehat{e}=\widetilde{p}-\widetilde{p}^{*} \\
\widehat{v}^{*}=\left(-\widetilde{p}^{*}+\widetilde{p}^{*}(f)+\widetilde{y}^{*}\right)-\widetilde{c}^{*}-\widetilde{g}^{*} \\
(-\widetilde{p}+\widetilde{p}(h)+\widetilde{y})-\widetilde{c}-\widetilde{g}
\end{gathered}
$$

Equations (23) to (41) are respectively the log-linearized versions of home and foreign price indexes, demand equations, labour-leisure trade off equations, Euler equations, long-run human wealth, short and long-run money demand equations, long-run and short-run current account equations and the purchasing power parity equation. The long-run money demand equations (35) and (36) are functions of the long run log-deviation of the real interest rate. This is due to the fact that, with overlapping generations, the real interest rate is not tied down by the Euler equation in the simple way in which it was in Obstfeld and Rogoff $(1995,1996)$ and in Ganelli (2000). In the model presented in this paper it would still be in principle possible to 
derive an expression for the long-run real interest rate using equation (18). The long run value of the real interest rate, however, being a function of human wealth, is affected by policies that, like the one that we are going to consider, involve intertemporal redistribution of taxation. This explains why, contrary to Obstfeld and Rogoff (1995, 1996) and Ganelli (2000), the long-run log-deviation of this variable is not zero in this model.

\section{Macroeconomic Effects of Government Debt}

In this section we consider a temporary reduction in taxes, financed by an increase in debt, with long-run taxes adjusting to pay for the higher interests. We introduce nominal rigidities in the form of one-period nominal stickiness in the domestic currency price of home goods and in the foreign currency price of foreign goods, as in Obstfeld and Rogoff $(1995,1996)$. The formal derivation of the effects of this policy is presented in the Appendix. In this section we rather provide some economic intuition underlying the results.

It is useful to notice that log-linearization of the government budget constraint (with constant money supply) around the initial steady state gives ${ }^{19}$

$$
\widetilde{g}=\widetilde{\tau}+\widehat{d}
$$

The policy that we are considering leaves government spending and short-run government debt unchanged. Therefore we have: $-\widetilde{\tau}=\widehat{d}$, i.e. the increase in long-run government debt is equal to the reduction in short-run taxes. ${ }^{20}$

This result, combined with log-linearization of the long-run government

\footnotetext{
${ }^{19}$ The variables that enter the government budget constraint, being all zero at the initial steady state, are normalized by initial consumption. For example $\widetilde{g}=\frac{d G_{t}}{C_{0}}$.

${ }^{20}$ As already stressed, in the initial steady state $\tau_{0}=0$ as well. A reduction in short-run taxes will therefore imply negative taxes, which can be thought of as a subsidy. The fact that taxes are negative does not alter our theoretical findings.
} 
budget constraint gives: $\left(R_{0}-1\right) \widehat{d}=-\left(R_{0}-1\right) \widetilde{\tau}=\widehat{\tau}$. The latter equality implies that the effects of a reduction in short-run taxes can be formally captured by an increase in long-run taxes. A possible solution strategy is therefore to find reduced forms in which long-run taxes appear as exogenous variables. ${ }^{21}$

\subsection{Short-run effects}

Using the equations listed in the previous section, together with the one period sticky-price hypothesis that allows us to set $\widetilde{p}(h)=\widetilde{p}^{*}(f)=0$, it is possible to reduce the log-linearized model to the two relationships

$$
\widetilde{e}=\Gamma_{5}\left(\widetilde{c}-\widetilde{c}^{*}\right)+\frac{1}{R_{0}} \frac{\Gamma_{1}}{\Gamma_{2}} \frac{1}{1+\psi}\left(\widehat{\tau}-\widehat{\tau}^{*}\right)
$$

and

$$
\begin{aligned}
\tilde{e}= & \Gamma_{4}\left(\widetilde{c}-\widetilde{c}^{*}\right)-\frac{\Gamma_{3} \Gamma_{1}}{\Gamma_{2}} \frac{1}{\left(R_{0}-1\right)} \frac{1}{(1+\psi)} \frac{1}{(\theta-1)}\left(\widehat{\tau}-\widehat{\tau}^{*}\right)+ \\
& +\frac{1}{\theta-1}\left(\widetilde{g}-\widetilde{g}^{*}\right)+\frac{1}{\left(R_{0}-1\right)} \frac{1}{(\theta-1)}\left(\widehat{g}-\widehat{g}^{*}\right)
\end{aligned}
$$

where the composite parameters are summarized in Table $1 .^{22}$

Table 1: Parameters of the model

$$
\begin{aligned}
& \Gamma_{1}=\frac{(1-q \beta)}{(1+\chi+\psi)}(1-q)(1+\psi) \frac{R_{0}}{R_{0}-q}>0 \\
& \Gamma_{2}=1-\Gamma_{1} \frac{\psi^{2}}{(\theta-1+\psi)(1+\psi)}>0 \\
& \Gamma_{3}=\frac{\theta-1+\psi \theta}{\theta-1+\psi}>0 \\
& \Gamma_{4}=\frac{\Gamma_{3}}{\Gamma_{2}} \frac{R_{0}}{R_{0}-1} \frac{q \beta}{(\theta-1)}+\frac{1}{\theta-1}>0 \\
& \Gamma_{5}=\frac{-R_{0}+1}{R_{0}}-\frac{1}{\Gamma_{2}} q \beta<0
\end{aligned}
$$

Furthermore, subtracting the foreign from the home demand equation, using the purchasing power parity equation and the sticky-price hypothesis

\footnotetext{
${ }^{21}$ Frenkel and Razin (1996) adopt a similar strategy.

${ }^{22}$ See the Appendix for a discussion of the signs.
} 
Figure 1: Effects of debt on relative consumption and the exchange rate

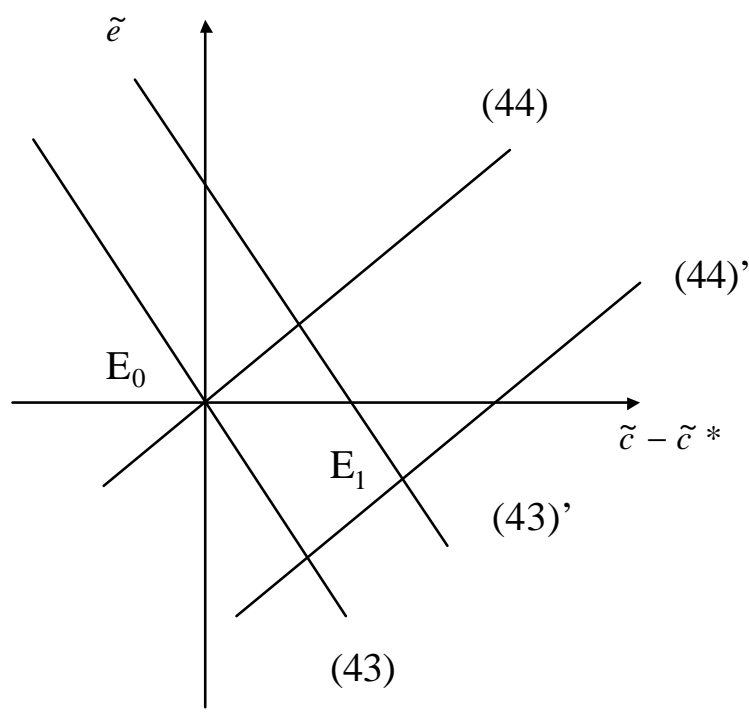

we derive a simple relationship between relative output and the nominal exchange rate

$$
\widetilde{y}-\widetilde{y}^{*}=\theta \widetilde{e}
$$

It is useful to notice that equations (43) and (44) constitute a pair of simultaneous equations in the two unknowns $\tilde{e}$ and $\widetilde{c}-\widetilde{c}^{*}$. From the discussion of the composite parameters presented in the Appendix, it can be proved that (43) is downward sloping in the $\left(\widetilde{e}, \widetilde{c}-\widetilde{c}^{*}\right)$ space, while (44) is upward sloping. Furthermore, an increase in future domestic taxes shifts both curves rightward. It follows that the effects of the policy that we are considering can be represented graphically in Figure 1 as a movement from $\mathrm{E}_{0}$ to $\mathrm{E}_{1}$.

The analysis carried out in Ganelli (2002) shows that this policy increases short-run consumption in a closed economy. In an open economy, however, the question arises of which of the two countries benefits more from it. The fact that, with finite life horizons, debt is perceived by agents as net wealth, implies an expansionary effect of the intertemporal reallocation of taxation 
on domestic short-run consumption. This has an expansionary effect on the other country, even if government spending is kept constant, due to the absence of home bias in private consumption. The domestic agents, on the other hand, will also discount the fact that with a positive probability they will be alive next period and will have therefore to pay higher taxes, while foreign agents will not have to worry about future higher taxes. Figure 1 shows clearly how all these different effects combine together to determine the final impact of the policy. A debt-financed tax cut always increases relative consumption. ${ }^{23}$

One of the obvious advantages of using an open economy setup is the possibility to assess the impact of fiscal policy on the exchange rate. In Figure 1, the effect on the exchange rate apparently depends on which curve shifts more to the right. The formal derivation of the results presented in the Appendix, however, allows us to establish rigorously that the situation depicted in Figure 1 is the only possible outcome, a temporary tax reduction implies a decrease in $\widetilde{e}$, i.e. an appreciation of the domestic currency.

The intuition for this result is that the increase in money demand, due to the increased relative consumption, determines an appreciation of the domestic exchange rate. The subsequent expenditure switching effect, expressed formally in equation (45), lowers relative output. This result should not be interpreted as implying that the fiscal shock has a recessionary effect on the Home country. We believe that the case in which both domestic and foreign output increase, with foreign output increasing more, is the most realistic one. In a version of the model with traded and non-traded goods, the expansionary effect of government spending on nontradables would counteract the expenditure-switching effect due to the appreciation of the exchange

\footnotetext{
${ }^{23}$ Solving for macroeconomic variables in relative terms is common in this literature. See, for example, Hau (2000) and Tille (2001).
} 
rate. ${ }^{24}$ This could mitigate, or reverse, the result that relative output falls.

Since on of the ambitions of the NOEM literature is to provide a new workhorse model for the analysis of macroeconomic interdependence, it is a natural exercise to compare our results to those of the two-country version of the MF model. ${ }^{25}$ Although, given the static nature of the latter, it is not possible to differentiate in it debt-financed from balanced-budget expansions, the effect of a fiscal shock in MF is still the relevant benchmark for comparison. In MF a fiscal expansion brings about an appreciation of the exchange rate. As stressed in Ganelli (2000), due to the reduction in consumption that follows a fiscal shock in a Ricardian setup, the Obstfeld and Rogoff (1995, 1996) Redux model produces the opposite result.

In the present model, the wealth effect (due to the presence of overlapping generations) that increases relative consumption, therefore appreciating the domestic currency, is the crucial link in making our results consistent with the MF ones. Introducing deviations from Ricardian equivalence allows us to bridge the gap between the old and the new paradigm in the analysis of macroeconomic interdependence.

It is important to stress again, however, that not only our model is able to restore in a microfounded framework the traditional Mundell-Fleming result, but it also allows us to do something that the Mundell-Fleming (and the Redux) model cannot do, namely it allows us to distinguish between the effects of different types of fiscal policy. ${ }^{26}$

The analysis carried out so far refers to the effects on relative variables. Ganelli (2000) points out how another important difference between the $R e$ $d u x$ and the MF model is related to the effect of fiscal policy on the level of

\footnotetext{
${ }^{24}$ See Lane and Perotti (2002).

${ }^{25}$ For a treatment of the two-country version of the MF model, see Dornbusch (1980).

${ }^{26}$ Using our framework we can analyze a debt-financed tax cut, a balanced-budget increase in government spending and debt financed increase in government spending, which can be thought as the sum of the first two (see section 4.2 for a more detailed discussion).
} 
output in the other country. In MF the output spillover is positive, while in the Redux model it is negative. In what follows we show how our model can reconcile the old and the new paradigm even on this point.

It is well known that a in a two-country model like the one we are presenting the level of a generic foreign variable can be decomposed as follows (see Aoki 1981)

$$
x^{*}=x^{w}-n\left(x-x^{*}\right)
$$

It follows that the results derived in this paper and those illustrated in the closed-economy version of this model presented in Ganelli (2002) allow us to remark on some effects on the levels of the variables, even without explicitly solving them in reduced forms. The world economy is here the sum of the home and of the foreign country. Perturbations that affect only one country's policy variables, leaving the other country's ones unchanged, will therefore affect world output and consumption in the same way as in Ganelli (2002).

Ganelli (2002) shows that a debt-financed tax cut increases world output when government spending is constant. Combining this with the reduction in relative output derived in this paper, formula (46) implies that the output spillover effect is, like in the MF framework, positive.

In summary, in the short-run a debt-financed tax cut increases relative consumption and decreases relative output. A naive interpretation of these results could lead us to conclude that tax cuts unambiguously increase relative welfare, because of the higher consumption and leisure enjoyed by the country that implements this policy relative to the other country. ${ }^{27}$ Using an intertemporal model, however, allows us to take into account the future effects of macroeconomic policies. In what follows we discuss the impact on net foreign assets and other long-run variables. Our model implies that the

${ }^{27}$ The welfare effects of real balances are usually assumed to be negligible in this literature. 
short-run increase in relative welfare can be reversed by the long-run effects on relative leisure and consumption, that go in opposite directions compared to the short-run ones.

\subsection{Long-Run Effects}

The long-run movements of output and consumption depend on the effect that government debt has on long-run net foreign assets. ${ }^{28}$ These can be investigated with the help of the following relationship, that can be derived from the system of log-linearized equations that constitute our model

$$
\widehat{v}=(1-n)\left[(\theta-1) \widetilde{e}-\left(\widetilde{c}-\widetilde{c}^{*}\right)-\left(\widetilde{g}-\widetilde{g}^{*}\right)\right]
$$

Equation (47) tells us that an appreciation of the short-run nominal exchange rate decreases long-run net foreign assets. ${ }^{29}$ Furthermore, long-run net foreign assets are a negative function of short-run relative consumption and relative government spending. Since under the policy that we are considering government spending is kept constant, we only need to worry about the first two effects. We know from the previous sections that a temporary tax cut always increases short-run relative consumption and appreciates the short-run exchange rate (i.e. it lowers $\widetilde{e}$ ). Summing up these two effects in equation (48) implies that long-run net foreign assets decrease following a temporary debt-financed tax cut.

Using the equations of the model it is also possible to derive the following relationship between long-run net foreign assets and relative consumption

\footnotetext{
${ }^{28}$ In empirical work, Lane and Milesi-Ferretti (2002) find that the level of government debt is an important driver of the net foreign asset position for both industrial and developing countries.

${ }^{29}$ Because of the way in which we defined the exchange rate, a decrease in $\widetilde{e}$ denotes an appreciation of the domestic currency.
} 


$$
\widehat{c}-\widehat{c}^{*}=\left(R_{0}-1\right)\left(\frac{\theta-1+\psi}{\theta-1+\psi \theta}\right) \widehat{v}
$$

that shows how the two variables vary in the same direction. Relative consumption therefore decreases in the long run. It is also possible to derive an expression for long-run relative output as a function of long-run net foreign assets as follows

$$
\widehat{y}-\widehat{y}^{*}=-\left(R_{0}-1\right)\left(\frac{\psi \theta}{\theta-1+\psi \theta}\right) \widehat{v}
$$

the above equation implies a negative relationship between relative output and net foreign assets. Following the policy that we are considering, therefore, long-run relative output increases.

The intuition behind the results that we derived is quite straightforward. Following a domestic temporary expansion in debt, short-run relative consumption increases. Obviously this worsen the net financial position of the home country relative to the foreign country. Furthermore, the increase in short-run relative domestic leisure makes the external position of the country even worse. This pushes domestic agents to decrease their long-run consumption of both goods and leisure, while the effect on foreign agents is symmetric. It follows that the above illustrated long-run changes in relative variables are achieved by an increase (decrease) in home output (consumption) and a reduction (increase) in foreign output (consumption). From the point of view of the domestic country, therefore, the debt financed tax-cut has detrimental welfare effects in the long run not only relative to the other country, but also in absolute terms.

The desirability of this policy from a welfare point of view will therefore depend on the weight that the government puts, in an aggregate social welfare function, on the utility of the generations currently alive compared to the one attached to the utility of future generations. 


\section{Policy Implications}

In this section we use the model presented in this paper as a theoretical benchmark in order to discuss some important policy issues already pointed out in the introduction, such as the effects of the tax cuts implemented by the Bush Administration in the US in 2001 and the effect of the "Golden Rule" introduced by the UK government on the value of the Pound.

\subsection{The US tax-cut}

The fiscal stimulus implemented by the Reagan administration in the 1980s, which consisted of a reduction in taxes associated with an increase in military spending, was widely believed to be one of the causes of the appreciation of the Dollar. In that circumstance, real world events proved to be conform to economic theory, in the sense that the Dollar reacted to the fiscal shock exactly how the (then dominant) MF paradigm would have predicted. Since the baseline Redux model predicts a depreciation of the domestic currency following a fiscal shock, it is not well equipped to explain exchange rate episodes such as those that followed Reagan's tax cut. The model presented in this paper, on the contrary, can reconcile an intertemporal approach with the empirical plausibility of the MF framework on this point.

In the present-day policy context, the Bush Administration has implemented a package of fiscal measures that resembles those put forward by Reagan in the 1980s. The fiscal plan presented to the Congress in February 2001 included estimated tax cuts for a total amount of about 1,6 trillion of Dollars, to be realised in the period 2002-2011. In May 2002, the Congress approved tax cuts for a total of about 1,35 trillion of Dollars. The Bush Administration presented these fiscal cuts as permanent ones, claiming that they will be financed by the estimated budget surpluses for the period under consideration. The Congressional Budget Office, however, estimated that 
the tax-cut plan will weaken the federal budget by about 1,8 trillions of Dollars by the end of 2011 (CBO 2001) and several observers have stressed the long-run sustainability problem posed by these measures (see, for example, Bergsten 2002). If these concerns are to be believed, Bush's fiscal policy can be seen as one that will necessary imply some kind of adjustment, involving an increase in taxes at some point in the future. The simple policy experiment that we have carried out in this paper could therefore contribute to explain some of the consequences of the 2001 tax cuts. From this point of view, although the appreciation of the US currency had already started since 1997, it is not implausible to argue that Bush's fiscal policy has contributed to the strength of the Dollar in 2001. A confirmation of this view can be found in the fact that simulations carried out by the National Institute's model of the world economy indicate that a large part of the appreciation of the Dollar exchange rate in the first quarter of 2001 can be attributed to the Bush plan (NIESR 2001).

Obviously, our stylised model does not consider a lot of important factors, most notably the endogenous response of the monetary authority to exchange rate changes. While we do not have the ambition, in this paper, to present a model that gives a full account of the appreciation of the US currency in the recent years, we believe that our analysis can contribute to explain how the tax-reduction policy can be considered as one factor (among the many) that has contributed to the strength of the Dollar.

The analogy with the Reagan tax cut also needs to be taken with a note of caution. As documented by Bergsten (2002), following the deterioration in the current account position due to the strength of the dollar in the period 1980-1985, the exchange rate fell by 50 percent during 1985-1987. However, the US were in the 1980s the world's largest creditor country, while today they are the largest debtor. This implies that the negative effects of a tax-cut 
policy on the exchange rate could manifest themselves quicker than in the 1980s.

\subsection{Debt Financed Versus Balanced Budget Govern- ment Spending: Exchange Rate Implications of the UK Golden Rule}

The theoretical results derived in this paper have some implications for the comparison of different methods of financing public expenditure. In particular, a debt-financed increase in government spending can be thought of as the sum of a balanced-budget increase in government spending and of a debt financed tax cut. Combining equations (43) and (44) it is possible to derive the following reduced form for the exchange rate in which the "debt" effect and the "balanced-budget" effect appear explicitly

$$
\begin{aligned}
\widetilde{e}= & \frac{1}{\frac{1}{\Gamma_{5}}-\frac{1}{\Gamma 4}} \frac{\Gamma_{1}}{\Gamma_{2}} \frac{1}{(1+\psi)}\left(\frac{1}{\Gamma_{5} R_{0}}+\frac{\Gamma_{3}}{\Gamma_{4}} \frac{1}{(\theta-1)} \frac{1}{\left(R_{0}-1\right)}\right)\left(\widehat{\tau}-\widehat{\tau}^{*}\right)+ \\
& -\frac{1}{\theta-1} \frac{\frac{1}{\Gamma 4}}{\frac{1}{\Gamma_{5}}-\frac{1}{\Gamma 4}}\left(\widetilde{g}-\widetilde{g}^{*}\right)
\end{aligned}
$$

We already know that the "debt" effect tends to appreciate the exchange rate. On the contrary, the "balanced-budget" effect, consistently with the Redux result, tends to depreciate it. ${ }^{30}$ It follows that, for a given level of government spending, the effects on the exchange rate can potentially be opposite depending on wether the fiscal shock is financed by lump-sum taxes or by debt. ${ }^{31}$

\footnotetext{
${ }^{30}$ Notice that $\frac{1}{\Gamma 4} /\left(\frac{1}{\Gamma_{5}}-\frac{1}{\Gamma 4}\right)<0$. See the Appendix for a discussion of the parameters.

${ }^{31}$ Noticing that $\Gamma_{1}$ approaches zero as $q$ approaches unity, equation (53) suggests that the "debt" effect is more likely to dominate when the deviation from Ricardian equivalence is large.
} 
This theoretical analysis can help us understanding the effects that policies based on limiting the size of budget deficits, such as the "Golden Rule" proposed by the UK government, can have on the level of the exchange rate. The "Golden Rule", that reflects the principles enshrined in the Finance Act 1998 and in the Code for Fiscal Stability, approved by the House of Commons in December 1998, requires that, over the economic cycle, the government borrows only to invest and not to fund current spending.

The concerns of the UK government in introducing such a rule were related to the need of ensuring the solvency of public finances and intergenerational fairness. While we do not intend to take any stance, in this paper, on the debate on whether the "Golden Rule" is either a necessary or a desirable instrument in order to achieve these goals, we would like to stress the (probably unintentional) implications of the "Golden Rule" for the issue of UK membership in the EMU.

One of the concerns on this point is, in fact, linked to the strong value of the Pound. It is widespread opinion that, if the UK decided to join the EMU, a devaluation of the Pound would be desirable before joining. While an official realignment would probably be unfeasible for political reasons, our theoretical analysis suggests that imposing the constraint that current government spending can only be financed by an increase in current taxation can have the effect of reducing (or of limiting the appreciation of) the Pound/Euro exchange rate.

From this point of view, the Golden Rule would seem at least as desirable as the fulfillment of the other economic tests proposed by the UK government, as a requirement to be satisfied prior joining the EMU. ${ }^{32}$ As already stressed in the introduction, an example of the "balanced-budget approach" that the

\footnotetext{
${ }^{32}$ Although our model is a two-country one, the fact that equation (53) is independent of the size parameter $n$ implies that it can be used to analyze Pound/Euro exchange rate issues.
} 
UK government chose to follow is given by the fact that the health spending announced by the Chancellor for the 2002 Budget implies a simultaneous increase in current taxes. On the basis of the analytical results of our model, we expect the exchange rate effects of the UK fiscal expansion to be different from the US ones.

\section{Conclusions}

This paper combines the Obstfeld and Rogoff $(1995,1996)$ framework with an overlapping generations structure of the Blanchard (1985) type. Analytical results suggest that a temporary reduction in taxation by the domestic country, matched by an increase in long-run taxes to meet the increased interests burden, unambiguously raises short-run relative consumption. The effect of the latter on relative money demand also implies an appreciation of the nominal exchange rate and a reduction of relative output in the short-run. The international output spillover is unambiguously positive in the shortrun. These results represent a significant step forward in reconciling the old and the new paradigms for the analysis of fiscal policy interdependence.

The increase in short-run relative consumption reduces long-run net foreign assets, and this has, in turn, a negative effect on long-run domestic consumption and leisure. The latter effects are also reinforced by the shortrun increase in relative leisure.

The main advantage of using a non-Ricardian setup is the possibility of comparing the effects of different types of fiscal policy. Our model shows that the exchange rate effects of a balanced-budget increase in government spending are opposite to the ones that follow a debt-financed tax cut. The

policy implications of these results in relation to current events in the US and UK economies have been highlighted in the paper.

Although the econometric analysis of fiscal policy is a field still in its 
infancy, a number of authors have attempted to assess the dynamic impact of fiscal shocks on macroeconomic variables in a closed economy. A nonexhaustive list of papers include Blanchard and Perotti (2001), Fatas and Mihov (2000), Mountford and Uhlig (2002) and Perotti (2002).

One result highlighted by these researchers is the failure of both the Real Business Cycle and New Keynesian, infinite-horizons traditions to produce theoretical models that match the empirically documented positive response of consumption to fiscal shocks in the short run. Our analysis shows that introducing non-trivial deviations from Ricardian equivalence can help bridging the gap between theoretical and empirical research on this point. An empirical test of the implications of the model, that would extend the analysis of the above mentioned authors to the two-country case, is an interesting avenue to follow for future research. ${ }^{33}$

Also, building a version of the model with multi-period nominal rigidities and allowing for an endogenous response of the monetary authorities to exchange rate changes would allow to analyse an even wider range of policies. This would come, however, at the price of giving up the possibility of deriving analytical solutions.

\footnotetext{
${ }^{33}$ The author is currently working in this direction.
} 
Appendix

Formal derivations of the results

\section{Effects on Relative Consumption}

It is possible to combine equation (44) with equation (43) in order to derive a reduced form for relative consumption as follows:

$$
\begin{aligned}
\widetilde{c}-\widetilde{c}^{*}= & \frac{1}{\left(\Gamma_{5}-\Gamma_{4}\right)} \frac{\Gamma_{1}}{\Gamma_{2}(1+\psi)}\left[-\frac{1}{R_{0}}-\Gamma_{3} \frac{1}{(\theta-1)} \frac{1}{\left(R_{0}-1\right)}\right]\left(\widehat{\tau}-\widehat{\tau}^{*}\right)+ \\
& +\frac{1}{\left(\Gamma_{5}-\Gamma_{4}\right)} \frac{1}{\theta-1}\left(\widetilde{g}-\widetilde{g}^{*}\right)+ \\
& +\frac{1}{\left(\Gamma_{5}-\Gamma_{4}\right)} \frac{1}{R_{0}-1} \frac{1}{(\theta-1)}\left(\widehat{g}-\widehat{g}^{*}\right)
\end{aligned}
$$

As explained before, the effect of a reduction in domestic short-run taxes financed by debt is given by $-d\left(\widetilde{c}-\widetilde{c}^{*}\right) / d \widetilde{\tau}=\left(R_{0}-1\right)\left[d\left(\widetilde{c}-\widetilde{c}^{*}\right) / d \widehat{\tau}\right]$. From equation (51), we can see that the latter is equal to: ${ }^{34}$

$$
\left(R_{0}-1\right) \frac{1}{\left(\Gamma_{5}-\Gamma_{4}\right)} \frac{\Gamma_{1}}{\Gamma_{2}(1+\psi)}\left[-\frac{1}{R_{0}}-\Gamma_{3} \frac{1}{(\theta-1)} \frac{1}{\left(R_{0}-1\right)}\right]
$$

In order to evaluate the final effect of the policy that we are considering we need therefore to determine the sign of the expression given in (52). We know that in the initial steady-state $R_{0}>\frac{1}{\beta}>1$, which ensures that $\left(R_{0}-1\right)=$ $r_{0}>0$. Furthermore, it implies that $\Gamma_{1}>0$. Since given the parameters we know that $\Gamma_{3}>0$, we can also conclude that the magnitude in the square bracket in equation (52) is negative. Assuming for the moment that $\Gamma_{2}>0$, we have $\frac{1}{\left(\Gamma_{5}-\Gamma_{4}\right)}<0$. If $\Gamma_{2}>0$ is true, therefore, the expression in (52) is the product of two negative terms (the one in the square bracket and $\left.\left(R_{0}-1\right) \frac{1}{\left(\Gamma_{5}-\Gamma_{4}\right)}\right)$ and of a positive one $\left(\frac{\Gamma_{1}}{\Gamma_{2}(1+\psi)}\right)$. In this case the policy that

\footnotetext{
${ }^{34}$ We are now keeping government spending fixed in both countries in every period. This implies $\widetilde{g}=\widetilde{g}^{*}=\widehat{g}=\widehat{g}^{*}=0$.
} 
we are considering would have a positive effect on relative consumption. In order to establish this result we need therefore to prove that $\Gamma_{2}$ is positive.

To demonstrate this, let's remember that in the case in which the agents have infinite life $R_{0}$ takes the value $\frac{1}{\beta}$ in the initial steady state around which we are $\log$-linearizing. Although we can not set $q$ exactly equal to 1 without making the model collapse to a Ricardian economy, substituting $R_{0}=\frac{1}{\beta}$ in $\Gamma_{2}$ can give some insight on what the effect will be in situations in which the deviation from Ricardian equivalence is not too large. Noticing that $\Gamma_{2}$ can be written as

$$
\Gamma_{2}\left(R_{0}\right)=1-\frac{(1-q \beta)}{(1+\chi+\psi)}(1-q) \frac{R_{0}}{R_{0}-q} \frac{\psi^{2}}{(\theta-1+\psi)}
$$

we can evaluate its value at $R_{0}=\frac{1}{\beta}$ as:

$$
\Gamma_{2}\left(\frac{1}{\beta}\right)=1-\frac{(1-q)}{(1+\chi+\psi)} \frac{\psi^{2}}{(\theta-1+\psi)}
$$

and the latter expression is clearly positive. A generalisation of this result follows if we notice that, holding other things constant, $\Gamma_{2}\left(R_{0}\right)$ is increasing in $R_{0}$ (because $\frac{R_{0}}{R_{0}-q}$ is decreasing in $R_{0}$ ). Therefore, when we remove the "approximation" that $R_{0}=\frac{1}{\beta}$, by restoring $R_{0}$ to its true value that is bigger than $\frac{1}{\beta}$, we simply strengthen the conclusion that $\Gamma_{2}\left(R_{0}\right)>0$. We can therefore conclude that the home country would benefit more than the foreign country, in terms of increased consumption, from implementing the policy that we are considering.

\section{Effects on Relative Output and the Exchange Rate}

We already know, from (45), that there is a simple relationship between relative output and the exchange rate. Solving for one of these two variables, therefore, also provides a reduced form for the other. The easiest way to do it is to put together equations (43) and (44), eliminating relative consumption from them. This yields the following reduced form for the exchange rate 


$$
\begin{aligned}
\widetilde{e}= & \frac{1}{\Gamma_{6}-\Gamma_{7}} \frac{\Gamma_{1}}{\Gamma_{2}} \frac{1}{(1+\psi)}\left(\frac{\Gamma_{6}}{R_{0}}+\Gamma_{3} \Gamma_{7} \frac{1}{(\theta-1)} \frac{1}{\left(R_{0}-1\right)}\right)\left(\widehat{\tau}-\widehat{\tau}^{*}\right)+ \\
& -\frac{1}{\theta-1} \frac{\Gamma_{7}}{\Gamma_{6}-\Gamma_{7}}\left(\widetilde{g}-\widetilde{g}^{*}\right)+ \\
& -\frac{\Gamma_{7}}{\Gamma_{6}-\Gamma_{7}} \frac{1}{(\theta-1)} \frac{1}{\left(R_{0}-1\right)}\left(\widehat{g}-\widehat{g}^{*}\right)
\end{aligned}
$$

where $\Gamma_{6}=\Gamma_{5}^{-1}$ and $\Gamma_{7}=\Gamma_{4}^{-1}$. The last equation and equation (45) imply that the effects of the policy that we are considering on the exchange rate and on relative output are given by

$$
\begin{aligned}
-d \widetilde{e} / d \widetilde{\tau}= & \left(R_{0}-1\right) d \widetilde{e} / d \widehat{\tau}= \\
= & \left(R_{0}-1\right) \frac{1}{\Gamma_{6}-\Gamma_{7}} \frac{\Gamma_{1}}{(1+\psi)} \frac{1}{\Gamma_{2}}\left[\frac{1}{\Gamma_{5}} \frac{1}{R_{0}}+\right. \\
& \left.+\frac{\Gamma_{3}}{\Gamma_{4}} \frac{1}{(\theta-1)} \frac{1}{\left(R_{0}-1\right)}\right]
\end{aligned}
$$

and

$$
\begin{aligned}
-d\left(\widetilde{y}-\widetilde{y}^{*}\right) / d \widetilde{\tau}= & \left(R_{0}-1\right) d\left(\widetilde{y}-\widetilde{y}^{*}\right) / d \widehat{\tau}= \\
= & \theta\left(R_{0}-1\right) \frac{1}{\Gamma_{6}-\Gamma_{7}} \frac{\Gamma_{1}}{(1+\psi)} \frac{1}{\Gamma_{2}}\left[\frac{1}{\Gamma_{5}} \frac{1}{R_{0}}+\right. \\
& \left.+\frac{\Gamma_{3}}{\Gamma_{4}} \frac{1}{(\theta-1)} \frac{1}{\left(R_{0}-1\right)}\right]
\end{aligned}
$$

To determine the effect of a temporary reduction in taxes, formally captured by an increase in long-run taxes, let's notice that we already know that $\theta\left(R_{0}-1\right) \frac{1}{\Gamma_{6}-\Gamma_{7}} \frac{\Gamma_{1}}{(1+\psi)} \frac{1}{\Gamma_{2}}<0$ in the selected steady state. The sign of the effect will therefore depend on the sign of the expression in square brackets in equations (55) and (56). With simple algebraic rearrangements, the latter can be shown to be equal to

$$
\frac{1}{R_{0} \frac{1}{\Gamma_{2}} q \beta+\frac{\left(R_{0}-1\right)}{\Gamma_{3}}}-\frac{1}{R_{0} \frac{1}{\Gamma_{2}} q \beta+\left(R_{0}-1\right)}
$$


(57) will be bigger than zero as:

$$
1<\frac{\theta-1+\psi \theta}{\theta-1+\psi}=\Gamma_{3}
$$

Since the condition for the latter equality to be satisfied is $\theta>1$, that is always true, the term that we are evaluating is always positive. This in turn means that $\left(R_{0}-1\right) d \widetilde{e} / d \widehat{\tau}$ and $\left(R_{0}-1\right) d\left(\widetilde{y}-\widetilde{y}^{*}\right) / d \widehat{\tau}$ are negative: a temporary tax reduction undertaken by the home country appreciates the domestic currency and lowers relative output. 


\section{References}

[1] Aoki, M., 1981, Dynamic Analysis of Open Economies. New York: Academic Press.

[2] Bergsten, C.F., (2002), "Can the United States Afford the Tax Cuts of 2001?", mimeo, presented at the 2002 Annual Meeting of the American Economic Association.

[3] Blanchard, O.J., (1985), "Debt, Deficits and Finite Horizons", Journal of Political Economy 93, 223-247.

[4] Blanchard, O.J. and R. Perotti (2001), "An Empirical Characterization of the Dynamic Effects of Changes in Government Spending and Taxes on Output," mimeo, MIT.

[5] Caselli, P. (2001), "Fiscal Consolidation under Fixed Exchange Rates", European Economic Review, Vol. 45 (3), pp. 425-450.

[6] Congressional Budget Office (2001), The Budget Outlook (August).

[7] Corsetti, G. and P. Pesenti, 2001, "Welfare and Macroeconomic Interdependence", Quarterly Journal of Economics 116: 421-445.

[8] Dornbusch, R. (1980). Open Economy Macroeconomics. Basic Books, New York.

[9] Fatas, A. and Mihov, I. (2000) "The Effects of Fiscal Policy on Consumption and Employment: Theory and Evidence", mimeo, INSEAD

[10] Fleming, M. (1962) "Domestic Financial Policies Under Fixed and Under Floating Exchange Rates", IMF Staff Papers Vol. 9.

[11] Frenkel and Razin, 1996, Fiscal Policy and Growth in the World Economy, eds. MacMillan. 
[12] Ganelli, G. (2000), "Useful Government Spending, Direct Crowding-Out and Fiscal Policy Interdependence", Previously Warwick Working Paper in Economics n. 547. Forthcoming in the Journal of International Money and Finance.

[13] Ganelli, G. (2001), "Fiscal Policy Rules in an Overlapping Generations Model with Endogenous Labour Supply", mimeo, Trinity College Dublin.

[14] Ganelli, G. (2002), "Finite Horizons, Temporary Nominal Rigidities and Fiscal Policy", mimeo, Trinity College Dublin.

[15] Ganelli, G. and P. R. Lane (2002), "Dynamic General Equilibrium Analysis: The Open Economy Dimension", CEPR DP 3540. Forthcoming in Elements in Dynamic Macroeconomic Analysis (S. Altug, J. Chaddha, C. Nolan, eds), Cambridge University Press.

[16] Ghironi, F. (2000), "Towards New Open Economy Macroeconometrics", mimeo.

[17] Hau, H. (2000) "Exchange Rate Determination: The Role of Factor Price Rigidities and Nontradeables", Journal of International Economics Vol. 50, Issue 2 (April), pp. 421-447.

[18] Lane, P. R., (2001), "The New Open Economy Macroeconomics: a Survey", Journal of International Economics 54 (2), pp. 235-266.

[19] Lane, P. R. and G.M. Milesi-Ferretti (2002), "Long-Term Capital Movements" NBER Macroeconomics Annual 16, Forthcoming.

[20] Lane, P.R. and R. Perotti (2001), "The Importance of Composition of Fiscal Policy: Evidence from Different Exchange Rate Regimes", Trinity Economic Papers No. 16. Forthcoming in the Journal of Public Economics. 
[21] Leith, C. and S. Wren-Lewis (2002), "Compatibility Between Monetary and Fiscal Policy Under EMU", mimeo.

[22] Mountford, A. and H. Uhlig (2002), "What are the Effects of Fiscal Policy Shocks?", mimeo.

[23] Mundell, R.A. (1968). International Economics. Macmillan, New York.

[24] NIESR (2001), The World Economy, National Institute Economic Review No. 176 (April).

[25] Obstfeld, M. and K. Rogoff, (1995) "Exchange Rate Dynamics Redux", Journal of Political Economy Vol. 103, pp. 624-660.

[26] Obstfeld, M. and K. Rogoff, (1996), Foundations of International Macroeconomics (Ch 10) Cambridge, MA: MIT Press.

[27] Perotti, R., (2002), "Estimating the Effects of Fiscal Policy in OECD Countries" ECB Working Paper No. 168.

[28] Sarno, L., (2001), "Towards a New Paradigm in Open Economy Modelling: Where Do We Stand?" Federal Reserve Bank of St. Louis Review, pp.21-36.

[29] Tille, C. (2001), "The Role of Consumption Substitutability in the International Transmission of Monetary Shocks" Journal of International Economics Vol.53, Issue 2 (April), pp. 421-444.

[30] Weil, P. (1989), "Overlapping Families of Infinitely-Lived Agents" Journal of Public Economics Vol. 38 (March), pp. 183-198. 